\title{
THE INFLUENCE OF HYDRATING AGENTS ON THE HYDRATION OF INDUSTRIAL MAGNESIUM OXIDE
}

Short title: Influence of hydrating agents on MgO hydration

\author{
Kgabo P Matabola ${ }^{1}$, Elizabet M van der Merwe ${ }^{1^{*}}$, Christien A Strydom $^{2}$ and \\ Frederick J W Labuschagne ${ }^{3}$ \\ ${ }^{1}$ Department of Chemistry, P O Box 392, UNISA, 0003, South Africa \\ ${ }^{2}$ School of Physical and Chemical Sciences, North-West University, \\ Private Bag X6001, Potchefstroom, 2520, South Africa \\ ${ }^{3}$ Department of Chemical Engineering, University of Pretoria, Lynwood Road, Pretoria, 0002
}

\begin{abstract}
BACKGROUND: The influence of different hydrating agents on the $\mathrm{pH}$ of the hydrating solutions, rate of hydration of $\mathrm{MgO}$ to $\mathrm{Mg}(\mathrm{OH})_{2}$ and product surface area was studied as a function of temperature of hydration. Hydrating agents used were aqueous solutions of ammonium chloride, magnesium acetate, magnesium nitrate, nitric acid, acetic acid, magnesium chloride, sodium acetate and hydrochloric acid and distilled water as control.
\end{abstract}

RESULTS: There was not a significant difference in the hydration behavior of the hydrating agents up to $50{ }^{\circ} \mathrm{C}$, where less than $10 \%$ of magnesium hydroxide was formed. The amount of hydroxide increased at temperatures above $60{ }^{\circ} \mathrm{C}$. When compared to the hydration in water, all the hydrating agents with the exception of sodium acetate showed a significant increase in the degree of hydration. Sodium acetate formed the lowest amount of magnesium hydroxide, ranging between 1.2 and $12.2 \%$ magnesium hydroxide. The largest percentage (56.7\%) magnesium hydroxide was formed from the hydration in magnesium acetate.

CONCLUSION: It seems that MgO hydration is a dissolution-precipitation process controlled by the dissolution of $\mathrm{MgO}$. The increased degree of hydration in magnesium acetate is possibly due to the presence of acetate and $\mathrm{Mg}^{2+}$ ions.

Keywords magnesium oxide, hydration, magnesium acetate, acetic acid, temperature and $\mathrm{pH}$

\footnotetext{
${ }^{\star}$ Corresponding author

Current address: Department of Chemistry, University of Pretoria, Pretoria, 0002

e-mail: liezel.vandermerwe@up.ac.za
} 


\section{Introduction}

Magnesium hydroxide is the magnesium compound mostly used as flame-retardant in organic polymeric materials ${ }^{1}$. It can be found naturally as the mineral called brucite, or can be produced from the hydration of magnesium oxide ${ }^{2}$. The process of magnesium oxide hydration should be carefully controlled so as to obtain a high quality product with the desired properties. Rapid hydration of magnesia will result in the formation of relatively big hydroxide aggregates consisting of submicroscopic crystallites with a very high surface area-particle morphology which is totally unacceptable for certain applications ${ }^{3}$.

Feitknecht and Braun ${ }^{4}$ synthesized magnesium hydroxide by the hydration of magnesium oxide in water vapour and the following reaction mechanism was proposed:

(1) Water vapour is physically adsorbed to form a liquid layer on the surface of the solid,

(2) the water reacts with the $\mathrm{MgO}$ to form a surface layer of magnesium hydroxide,

(3) the magnesium hydroxide dissolves in the water layer, and finally

(4) as the water layer becomes saturated with $\mathrm{Mg}(\mathrm{OH})_{2}$, precipitation takes place.

Literature further indicates that two surface chemical reactions take place when MgO reacts with water and goes into solution as $\mathrm{Mg}(\mathrm{OH})_{2}{ }^{5}$. These are the formation of $\mathrm{Mg}(\mathrm{OH})_{2}$ and the removal of $\mathrm{Mg}(\mathrm{OH})_{2}$ from the $\mathrm{MgO}$ surface. It was suggested that the rate controlling step is the removal of the $\mathrm{Mg}(\mathrm{OH})_{2}$ layer as $\mathrm{Mg}^{2+}$ and $\mathrm{OH}^{-}$ions from the $\mathrm{MgO}$ surface ${ }^{4,5}$.

Filippou ${ }^{3}$ studied the kinetics of MgO hydration in diluted magnesium acetate solutions and found that a high-quality magnesium hydroxide can be produced. They also suggested that the hydration process is a dissolution-precipitation process controlled by the dissolution of $\mathrm{MgO}$. Their proposed mechanism for hydration in the presence of acetate ions is as follows:

(1) Magnesium acetate dissociation:

$\left(\mathrm{CH}_{3} \mathrm{COO}\right)_{2} \mathrm{Mg}(\mathrm{aq}) \leftrightarrow 2 \mathrm{CH}_{3} \mathrm{COO}^{-}(\mathrm{aq})+\mathrm{Mg}^{2+}(\mathrm{aq})$

(2) Magnesia dissolution:

$\mathrm{MgO}(\mathrm{s})+\mathrm{CH}_{3} \mathrm{COO}^{-}(\mathrm{aq})+\mathrm{H}_{2} \mathrm{O}(\mathrm{I}) \leftrightarrow \mathrm{CH}_{3} \mathrm{COOMg}^{+}(\mathrm{aq})+2 \mathrm{OH}^{-}(\mathrm{aq})$

or even by direct attack by acetic acid which is formed in the bulk of the solution:

$\mathrm{CH}_{3} \mathrm{COO}^{-}(\mathrm{aq})+\mathrm{H}_{2} \mathrm{O}(\mathrm{I}) \rightarrow \mathrm{CH}_{3} \mathrm{COOH}(\mathrm{aq})+\mathrm{OH}^{-}(\mathrm{aq})$

$\mathrm{MgO}(\mathrm{s})+\mathrm{CH}_{3} \mathrm{COOH}(\mathrm{aq}) \rightarrow \mathrm{CH}_{3} \mathrm{COOMg}^{+}(\mathrm{aq})+\mathrm{OH}^{-}(\mathrm{aq})$

(3) Dissociation of magnesium complexes and magnesium hydroxide precipitation in the bulk of the solution due to supersaturation: 


$$
\begin{aligned}
& \mathrm{CH}_{3} \mathrm{COOMg}^{+}(\mathrm{aq}) \rightarrow \mathrm{CH}_{3} \mathrm{COO}^{-}(\mathrm{aq})+\mathrm{Mg}^{2+}(\mathrm{aq}) \\
& \mathrm{Mg}^{2+}(\mathrm{aq})+2 \mathrm{OH}^{-}(\mathrm{aq}) \rightarrow \mathrm{Mg}(\mathrm{OH})_{2}(\mathrm{~s})
\end{aligned}
$$

Van der Merwe ${ }^{2}$ studied the extent to which different parameters (concentration of magnesium acetate, solution temperature and solid to liquid ratio of $\mathrm{MgO}$ ) influence the hydration rate of a medium reactive magnesium oxide. Various other ions in solutions may influence the rate of formation of the hydroxide. Strydom ${ }^{1}$, Birchal ${ }^{6}$ and Maryska $^{7}$ studied the effects of calcining temperature and time on the hydration of industrially obtained magnesium oxide. They all found that the degree of hydration is influenced considerably by the calcining time and temperature.

Raschman ${ }^{8}$ studied the kinetics of the reaction between dead-burnt magnesia and hydrochloric acid. The effect of temperature, activity of $\mathrm{H}^{+}$ions, particle size and composition of the solid on the dissolution of magnesium oxide were investigated. Chemical dissolution of burnt magnesite in hydrochloric acid is a liquid-solid reaction in which no solid product is formed. The following overall hydration process was proposed which involved the following steps in series:

(1) Diffusion of $\mathrm{H}^{+}$ions through the liquid film at the liquid-solid interface to the surface of the solid particles,

(2) Surface chemical reaction according to the equation below:

$$
\mathrm{MgO}(\mathrm{s})+2 \mathrm{H}^{+}(\mathrm{aq}) \rightarrow \mathrm{Mg}^{2+}(\mathrm{aq})+\mathrm{H}_{2} \mathrm{O}(\mathrm{l})
$$

(3) Diffusion of liquid products from the interface through the film to the bulk liquid.

The effect of temperature and $\mathrm{pH}$ on the degree of hydration and product surface area were studied and the influence of different hydrating agents on the hydration of industrially obtained magnesium oxide over the temperature range of $30^{\circ} \mathrm{C}$ to $80^{\circ} \mathrm{C}$ were evaluated.

\section{Experimental}

\section{Materials}

All chemicals used were of analytical grade, with the exception of solid magnesia (MgO) and the distilled water that was used for solutions. The magnesia used in this investigation was obtained from the calcination of highly reactive magnesia (caustic or light burned magnesia) in an electric furnace at $1200^{\circ} \mathrm{C}$ for 1 hour using high temperature crucibles. The calcined magnesia was of an intermediate quality between medium and hard-burnt magnesia with a BET-measured surface area of $5.0 \mathrm{~m}^{2} / \mathrm{g}$. The highly reactive magnesia (caustic magnesia) was supplied by Chamotte Holdings (PTY) LTD, a mining company in South Africa. It had been produced by the calcination of natural 
magnesite mineral $\left(\mathrm{MgCO}_{3}\right)$ between $800{ }^{\circ} \mathrm{C}$ and $900{ }^{\circ} \mathrm{C}$ in an electric rotary kiln for approximately 30 minutes. The specific surface area of the reactive magnesia was $73.48 \mathrm{~m}^{2} / \mathrm{g}$.

\section{Instrumentation}

A Q500 TGA from TA Instruments was used to perform the thermogravimetric analyses. For all the analyses, a heating rate of $10{ }^{\circ} \mathrm{C} / \mathrm{min}$ was used under a $\mathrm{N}_{2}$ atmosphere. Platinum pans were used and the sample masses were approximately $10 \mathrm{mg}$.

The X-ray fluorescence analyses were performed on an ARL9400XP + spectrometer. The samples were ground to $<75 \mu \mathrm{m}$ in a tungsten carbide milling vessel and roasted at $1000{ }^{\circ} \mathrm{C}$ to determine the loss on ignition value. A mixture of $1 \mathrm{~g}$ sample and $6 \mathrm{~g} \mathrm{Li}_{2} \mathrm{~B}_{4} \mathrm{O}_{7}$ was then fused into a glass slide. Major element analyses were executed on the fused bead.

X-ray powder diffraction analyses were done on an automated Siemens D-501 spectrometer with a 40-position sample changer and monochromated $\mathrm{Cu}$ Ka radiation. The samples were prepared using standard Siemens sample holders and the powdered samples were pressed into the holder using a glass slide.

A Nova 1000e Surface Area and Pore Size Analyzer, using nitrogen gas as the adsorbent, was used to determine the surface areas of both $\mathrm{MgO}$ and the products

\section{Citric acid reactivity test}

The reactivity of the magnesium oxide samples used in this investigation was determined by the industrially used citric acid reactivity test. In this test, $100 \mathrm{ml}$ of a $0.4 \mathrm{~N}$ citric acid solution with 5 drops of phenolphthalein indicator is added to $2.0 \mathrm{~g}$ of powdered magnesium oxide. The mixture is shaken until the colour changes from white to pink. The time in seconds needed to neutralize the acid completely is then reported as the citric acid reactivity.

\section{Hydration procedure}

The following procedure was followed to study the influence of each hydrating agent on the hydration of magnesium oxide.

A $35.0 \mathrm{~g}$ sample of magnesia (as obtained from the supplier) was calcined at $1200{ }^{\circ} \mathrm{C}$ for 1 hour. The sample was allowed to cool to room temperature. It was hand ground in a porcelain mortar and pestle to break the large lumps and then milled for 30 seconds with an Ika electric mill. The sample was then sieved for 5 minutes to a particle size of less than $75 \mu \mathrm{m}$ with an Electromagnetic Sieve Shaker EMS-8. To hydrate the MgO, $10 \mathrm{~g}$ of the calcined sample was stirred at a constant rate of $250 \mathrm{rpm}$ in a $100 \mathrm{ml}$ of a $0.1 \mathrm{M}$ hydrating solution, while the temperature was controlled by 
performing the reaction in a water bath at temperatures ranging between $30^{\circ} \mathrm{C}$ and $80{ }^{\circ} \mathrm{C}$ for 30 minutes. The hydrating agents used were ammonium chloride, magnesium acetate, magnesium nitrate, nitric acid, acetic acid, water, magnesium chloride, sodium acetate and hydrochloric acid. The hydration experiments were repeated twice for all the hydrating agents and the average percentage of magnesium hydroxide was reported. The $\mathrm{pH}$ and temperature were measured simultaneously at one minute time intervals with a $\mathrm{pH} 510 \mathrm{pH} / \mathrm{mV} /{ }^{\circ} \mathrm{C}$ meter from Eutech Instruments. The stirrer was stopped at 25 minutes to allow the solids to settle for better filterability.

At the end of each experiment, the slurry was vacuum filtered. The solids remaining in the filter, consisting of reagent $\mathrm{MgO}$ and produced magnesium hydroxide, were washed two times with 50 $\mathrm{ml}$ water, dried at $200{ }^{\circ} \mathrm{C}$ for 2 hours and then hand ground with a porcelain mortar and pestle. The degree of hydration was determined by TG analysis.

\section{Results and discussion}

\section{XRF and XRD}

The chemical analysis of calcined magnesium oxide, as determined by XRF, is shown in Table 1. The chemical analysis shows that the calcined magnesium oxide consisted mainly of crystalline magnesium oxide. The calcined $\mathrm{MgO}$ contains $95 \%$ wt $\mathrm{MgO}$ and it was considered a relatively pure mineral. XRD analysis confirmed that the calcined $\mathrm{MgO}$ consisted mainly of periclase with a small amount of $\mathrm{SiO}_{2}$.

XRD spectra of the prducts after hydration at $80{ }^{\circ} \mathrm{C}$ indicated that the phases present after hydration were mainly $\mathrm{Mg}(\mathrm{OH})_{2}$ and unreacted $\mathrm{MgO}$, while small amounts of magnesite and quartz could also be observed.

\section{Variation of degree of hydration with hydration temperature and hydrating agents}

Figure 1 and Table 2 depict the percentage magnesium hydroxide formed as a function of temperature for the different hydrating agents. The hydration at $30{ }^{\circ} \mathrm{C}$ resulted in a very small amount of hydroxide being formed, ranging between $1.2 \%-2.9 \%$. At $40{ }^{\circ} \mathrm{C}$, the highest amount was obtained in magnesium nitrate with $4.8 \%$. Magnesium nitrate formed the largest percentage of magnesium hydroxide $(7.8 \%)$ at $50{ }^{\circ} \mathrm{C}$ and sodium acetate the least $(2.6 \%)$. All the other hydrating agents behaved similarly, with the amount of magnesium hydroxide being formed ranging between $4.2 \%$ and $5.8 \%$. At $60{ }^{\circ} \mathrm{C}$, ammonium chloride, magnesium acetate, nitric acid and acetic acid gave similar results $(9.0 \%$ - $9.6 \%)$ while an optimum amount was obtained upon hydration in hydrochloric acid and magnesium nitrate with $11.8 \%$ magnesium hydroxide being formed. 
A considerable increase in the amount of magnesium hydroxide was obtained at $70{ }^{\circ} \mathrm{C}$. The highest degree of hydration was obtained from the hydration performed in magnesium acetate with $23.9 \%$ magnesium hydroxide. Hydrochloric acid formed more hydroxide when compared to the hydrations performed in nitric acid and acetic acid. The hydrations done in ammonium chloride, magnesium nitrate and magnesium chloride gave approximately the same results.

The hydrations at $80{ }^{\circ} \mathrm{C}$ resulted in a maximum of the hydroxide being formed when compared to hydrations at $70^{\circ} \mathrm{C}$. The lowest amount of magnesium hydroxide was obtained in sodium acetate with $12.2 \%$. Hydration in magnesium nitrate and acetic acid resulted in the same amount of hydroxide being formed. Approximately the same amounts of the hydroxide were also obtained from the hydrations performed in ammonium chloride, nitric acid and hydrochloric acid. The highest percentage of magnesium hydroxide was obtained in magnesium acetate with $56.7 \%$. The optimum amount of the hydroxide formed at these higher temperatures is possibly due to the better solubility of the $\mathrm{MgO}$ at these temperatures.

\section{Variation of $\mathrm{pH}$ with hydration temperatures and hydrating agents}

Figure 2 depicts the variations of the hydration solution $\mathrm{pH}$ with temperature for the hydration of magnesium oxide in different hydrating agents. For all hydrating agents, a decrease in solution $\mathrm{pH}$ was observed when the hydration temperature was increased. For hydrations in water and sodium acetate, an increase in $\mathrm{pH}$ with time was observed.

Figure 3 depicts the variation of the average $\mathrm{pH}$ (obtained between 20 and 30 minutes of hydration) with temperature for the different hydrating agents. The trend in the variation is similar for all the hydrating agents, i.e., the $\mathrm{pH}$ decreases as the temperature increases. The hydrations performed in sodium acetate showed higher $\mathrm{pH}$ values when compared to the other hydrating agents while the hydrations performed in all other hydrating agents (hydrochloric acid, water, acetic acid, nitric acid, magnesium nitrate, magnesium chloride, ammonium chloride and magnesium acetate) have approximately similar $\mathrm{pH}$ values.

\section{Surface area}

Figure 4 summarises the specific surface areas of the products after 30 minutes of hydration within the temperature range of $30-80{ }^{\circ} \mathrm{C}$. The surface areas of the products, exclusive of products obtained from hydration performed in magnesium acetate and acetic acid, decreased slightly at a hydration temperature of $80^{\circ} \mathrm{C}$. Magnesium acetate and acetic acid showed an increase in product surface areas with increasing temperature. The products formed from hydration in water had surface areas close to those obtained from hydration in ammonium chloride, magnesiun nitrate, nitric acid, hydrochloric acid, sodium acetate and magnesium chloride 
Surface areas of $9.10 \mathrm{~m}^{2} / \mathrm{g}$ at $60{ }^{\circ} \mathrm{C}$ to $16.07 \mathrm{~m}^{2} / \mathrm{g}$ at $80{ }^{\circ} \mathrm{C}$ were obtained from the hydration in acetic acid. Upon hydration in magnesium acetate, surface areas of $10.47 \mathrm{~m}^{2} / \mathrm{g}$ at $60{ }^{\circ} \mathrm{C}$ and $28.44 \mathrm{~m}^{2} / \mathrm{g}$ at $80^{\circ} \mathrm{C}$ were obtained. Magnesium acetate was the hydrating agent that showed the strongest temperature dependence, with the highest product surface areas.

According to Fillipou $^{3}$, rapid hydration of magnesium oxide will result in the formation of relatively large hydroxide particles with high surface areas. This can explain the higher surface areas of products formed from the hydration in magnesium acetate and acetic acid. It seems that the products were formed at a rate that decreased the possibility of crystal formation or agglomeration ${ }^{9}$.

\section{Conclusions}

From the results and the literature, it seems that the mechanism of $\mathrm{MgO}$ hydration in different hydrating solution is complex, and depends on the hydrating solution and its $\mathrm{pH}^{9}$. The hydration of $\mathrm{MgO}$ is a dissolution-precipitation process, controlled by the dissolution of $\mathrm{MgO}^{10}$.

The results indicate that the degree of hydration is very sensitive to the hydration temperature. The optimum amount of magnesium hydroxide formed at higher temperatures is due to the better solubility of the $\mathrm{MgO}$ at higher temperatures and therefore the precipitation of magnesium hydroxide is high. The degree of hydration improved from $1.2 \%$ at $30{ }^{\circ} \mathrm{C}$ to $56.7 \%$ at $80{ }^{\circ} \mathrm{C}$. The increased degree of hydration from hydration performed in magnesium acetate can be attributed to the presence of acetate ions, the mechanism is described in the introduction ${ }^{3}$. The additional $\mathrm{Mg}^{2+}$ ions further enhance the degree of hydration in magnesium acetate.

The enhanced degree of hydration for hydrations performed in acidic hydrating agents seemed to be due to the higher concentrations of $\mathrm{H}^{+}$in the solution, increasing the solubility of $\mathrm{MgO}$ the following reaction:

$$
\mathrm{MgO}(\mathrm{s})+2 \mathrm{H}^{+}(\mathrm{aq}) \rightarrow \mathrm{Mg}^{2+}(\mathrm{aq})+\mathrm{H}_{2} \mathrm{O}(\mathrm{I})
$$




\section{References}

1. Strydom CA, Van der Merwe EM and Aphane ME, The effect of calcining conditions on the rehydration of dead burnt magnesium oxide using magnesium acetate as a hydrating agent. Journal of Thermal Analysis and Calorimetry 80(3) :659-662 (2005). DOI: 10.1007/s10973005-0710-x

2. Van der Merwe EM, Strydom CA and Botha A, Hydration of medium reactive industrial magnesium oxide with magnesium acetate - A Thermogravimetric study. Journal of Thermal Analysis and Calorimetry 77(1) :49-56 (2004). DOI: 10.1023/B:JTAN.0000033187.61971.1d

3. Fillipou D, Katiforis N, Papassiopi N and Adams K, On the kinetics of magnesia hydration in magnesium acetate solutions. Journal of Chemical Technology and Biotechnology 74 : $322-$ 328 (1999).

4. Feitknecht $\mathrm{W}$ and Braun $\mathrm{H}$, Der Mechanismus der Hydratation von Magnesiumoxid mit Wasserdampf. Helvetica Chimica Acta., 50 (7) : 2040-2053 (1967).

DOI: 10.1002/hlca.19670500738

5. Smithson GL and Bakhshi NN, The kinetics and mechanism of the hydration of magnesium oxide in a batch reactor. The Canadian Journal of Chemical Engineering, 47(6) : 508-513 (1969). DOI: $10.1002 /$ cjce.5450470602

6. Birchal VSS, Rocha SDF and Ciminelli VST, The effect of magnesite calcination conditions on magnesia hydration. Minerals Engineering, 13 (14-15) : 1629-1633 (2000).

7. Maryska M and Blaha J, Hydration kinetics of magnesium oxide, Part 3 - Hydration rate of $\mathrm{MgO}$ in terms of temperature and time of its firing. Ceramics-Silikaty, 41 (4) :121-123 (1997).

8. Raschman $P$ and Fedorockova A, Study of inhibiting effect of acid concentration on the dissolution rate of magnesium oxide during the leaching of dead-burned magnesite. Hydrometallurgy, 71 (3-4) : 403-412 (2004). DOI:10.1016/S0304-386X(03)00114-2

9. Van der Merwe EM and Strydom C, Hydration of medium reactive magnesium oxide using hydration agents. Journal of Thermal Analysis and Calorimetry 84 (2) :467-471 (2006). DOI: $10.1007 / \mathrm{s} 10973-005-7291-6$

10. Rocha SDF, Mansur MB and Ciminelli VST, Kinetics and mechanistic analysis of caustic magnesia hydration. Journal of Chemical Technology and Biotechnology, 79 : 816-821 (2004). DOI: 10.1002/jctb.1038 
Table 1. XRF analysis of calcined MgO

\begin{tabular}{cc}
\hline Composition & $\begin{array}{c}\text { \% wt } \\
\text { Calcined } \mathbf{~ M g O}\end{array}$ \\
\hline $\mathrm{SiO}_{2}$ & 3.41 \\
$\mathrm{TiO}_{2}$ & 0.00 \\
$\mathrm{Al}_{2} \mathrm{O}_{3}$ & 0.13 \\
$\mathrm{Fe}_{2} \mathrm{O}_{3}$ & 0.28 \\
$\mathrm{MnO}$ & 0.02 \\
$\mathrm{MgO}$ & 94.70 \\
$\mathrm{CaO}_{\mathrm{Na}}$ & 1.08 \\
$\mathrm{~K}_{2} \mathrm{O}$ & 0.03 \\
$\mathrm{P}_{2} \mathrm{O}_{5}$ & 0.01 \\
$\mathrm{Cr}_{2} \mathrm{O}_{5}$ & 0.01 \\
$\mathrm{NiO}$ & 0.02 \\
$\mathrm{~V}_{2} \mathrm{O}_{5}$ & 0.25 \\
$\mathrm{ZrO}$ & 0.00 \\
$\mathrm{LOI}$ & 0.00 \\
$\mathrm{Total}$ & 0.01 \\
\hline & 99.95 \\
\hline
\end{tabular}


Table 2. Percentage of $\mathrm{Mg}(\mathrm{OH})_{2}$ formed as a function of temperature

\begin{tabular}{|c|c|c|c|c|c|c|c|c|c|}
\hline Temperature, ${ }^{\circ} \mathrm{C}$ & $\mathrm{NH}_{4} \mathrm{Cl}$ & $\mathrm{Mg}\left(\mathrm{CH}_{3} \mathrm{COO}\right)_{2 \cdot} \cdot 4 \mathrm{H}_{2} \mathrm{O}$ & $\mathrm{MgNO}_{3}$ & $\mathrm{HNO}_{3}$ & $\mathrm{CH}_{3} \mathrm{COOH}$ & $\mathrm{H}_{2} \mathrm{O}$ & $\mathrm{MgCl}_{2} \cdot 6 \mathrm{H}_{2} \mathrm{O}$ & $\mathrm{NaCH}_{3} \mathrm{COO}$ & $\mathrm{HCl}$ \\
\hline 30 & 1.3 & 2.1 & 2.8 & 2.9 & 2.6 & 2.1 & 1.8 & 1.2 & 2.2 \\
\hline 40 & 1.4 & 2.9 & 4.8 & 4.7 & 3.2 & 2.7 & 4.1 & 1.8 & 4.2 \\
\hline 50 & 4.2 & 5.8 & 7.8 & 5.5 & 5.3 & 5.5 & 4.8 & 2.6 & 4.9 \\
\hline 60 & 9.3 & 9.5 & 11.8 & 9.4 & 9.6 & 7.5 & 9.0 & 3.8 & 11.8 \\
\hline 70 & 19.0 & 23.9 & 20.0 & 18.3 & 17.6 & 12.9 & 20.9 & 7.2 & 22.5 \\
\hline 80 & 39.7 & 56.7 & 44.4 & 38.8 & 44.5 & 16.1 & 33.1 & 12.2 & 39.1 \\
\hline
\end{tabular}




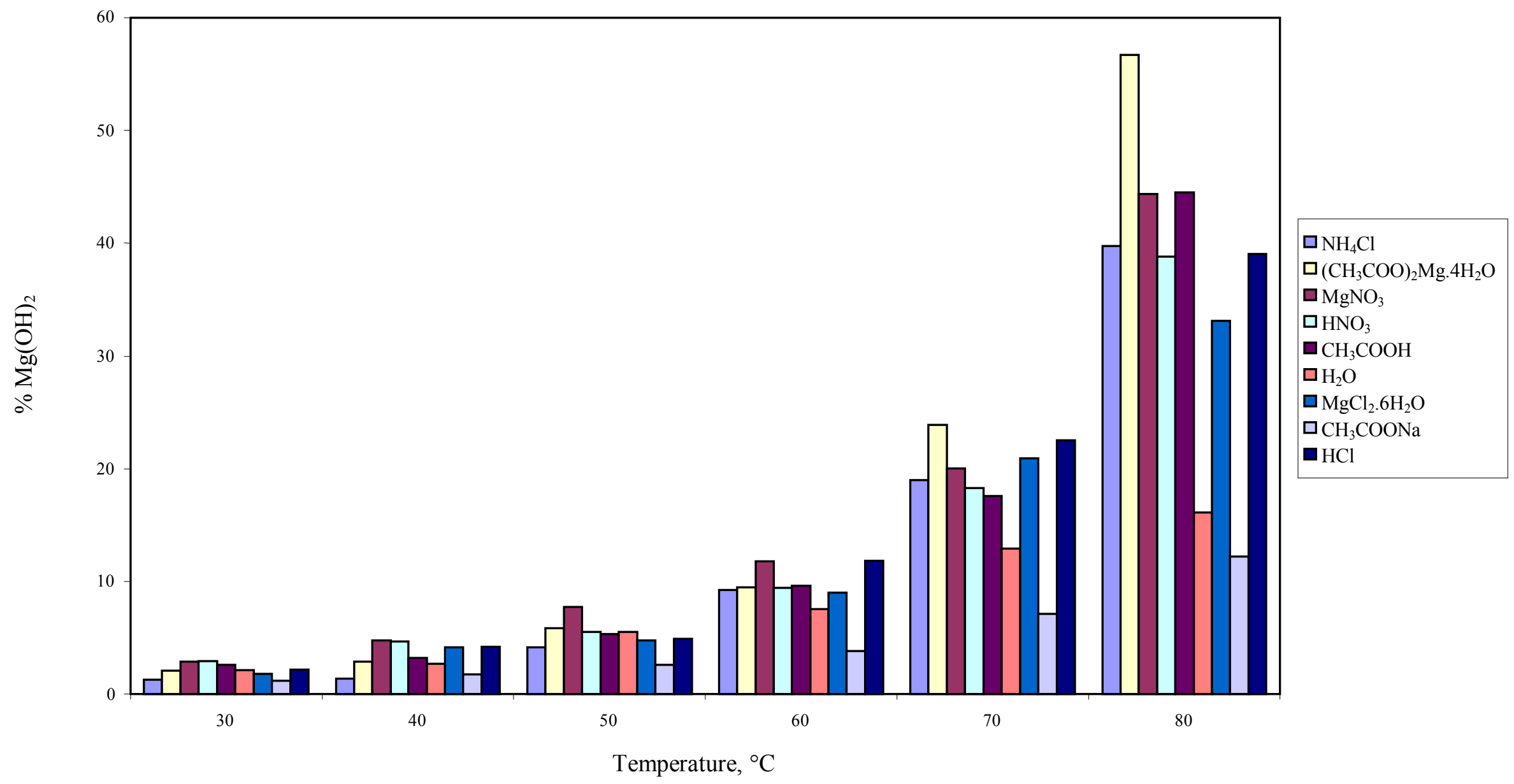

Figure 1. The degree of hydration as function of temperature for the different hydrating agents 


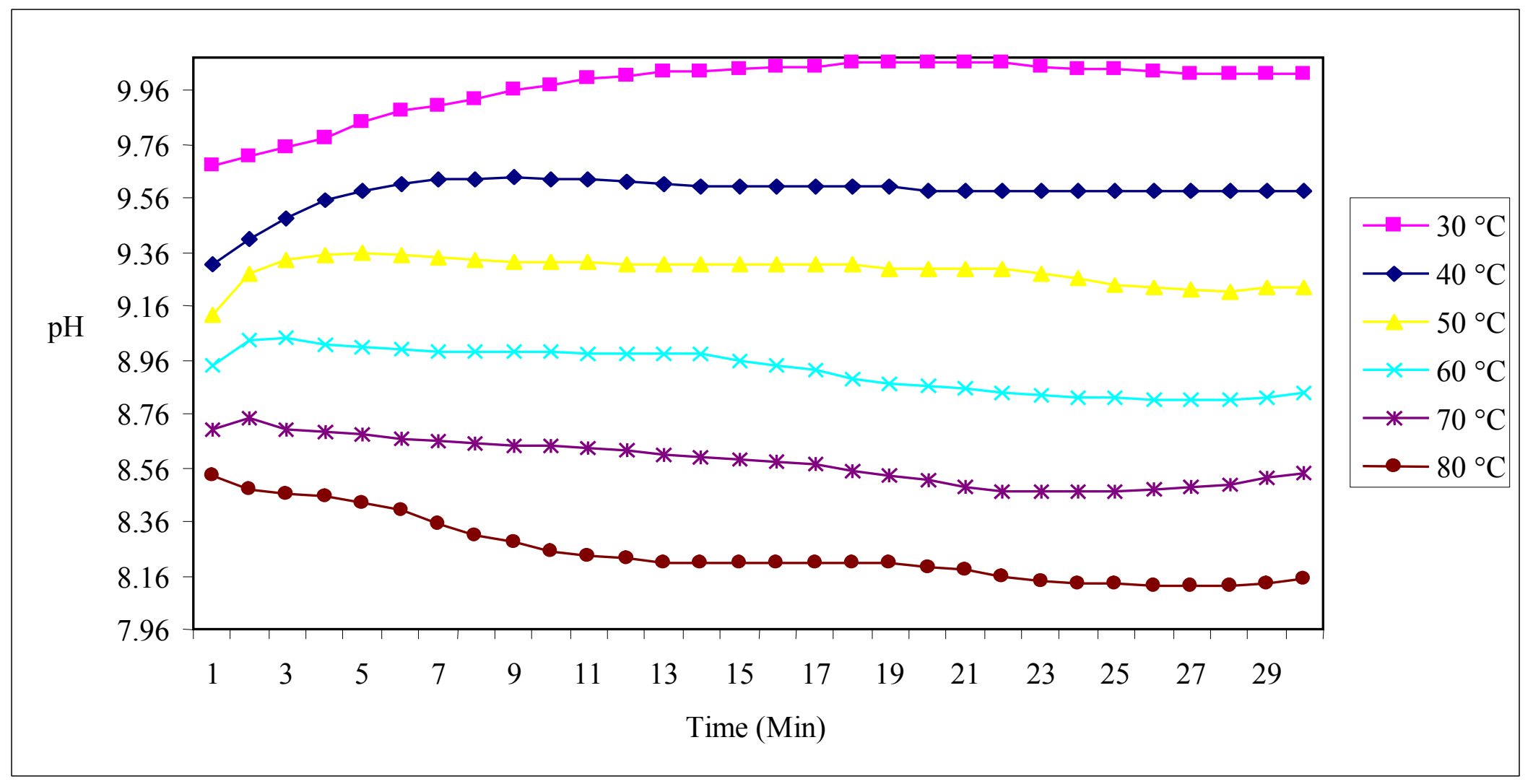

Figure 2. Variation of $\mathrm{pH}$ with temperature for the hydration of $\mathrm{MgO}$ in acetic acid 


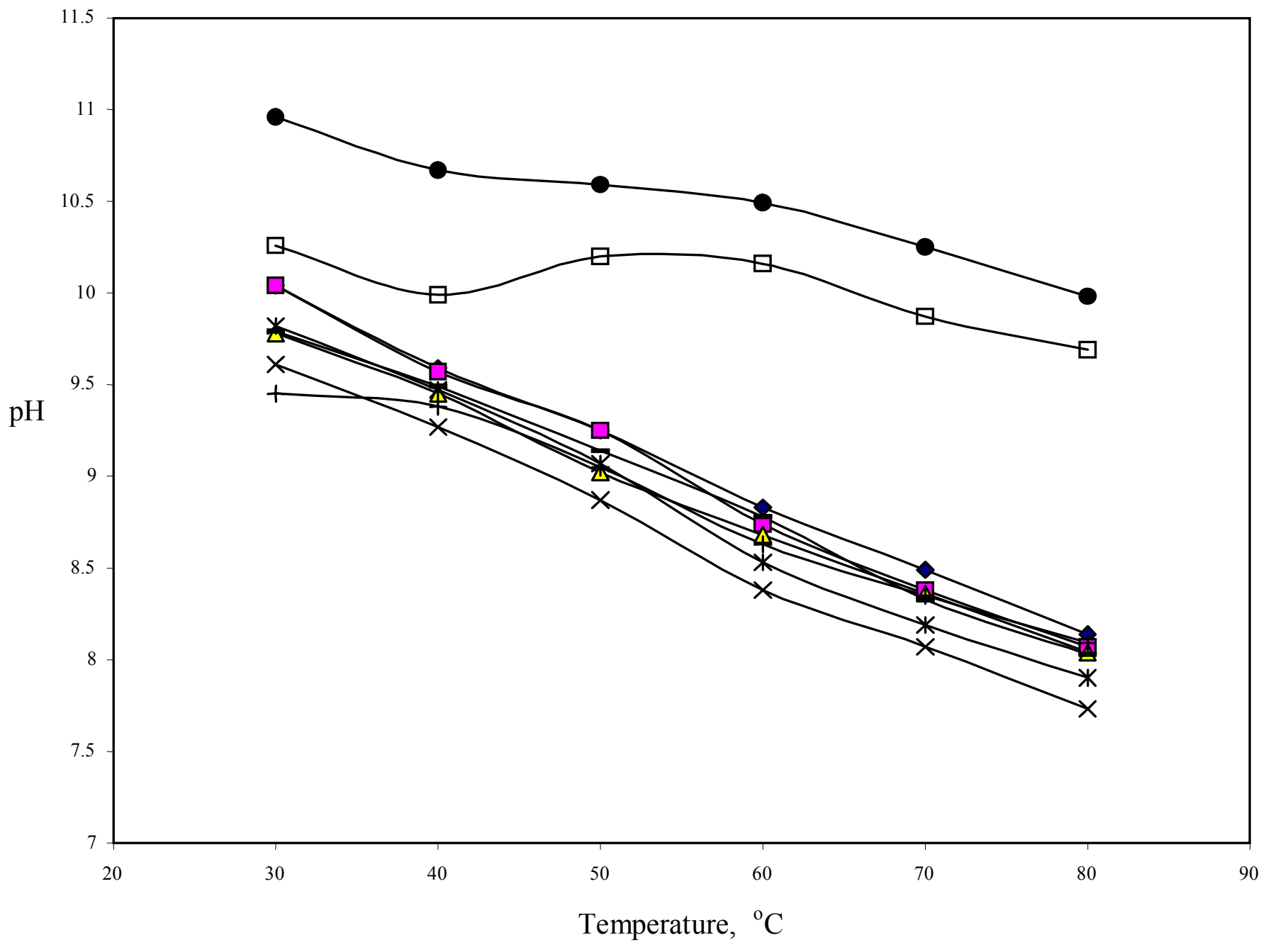

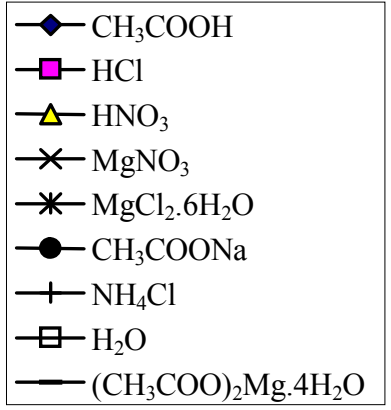

Figure 3. Variation of the average $\mathrm{pH}$ with hydration temperature for the different hydrating agents 


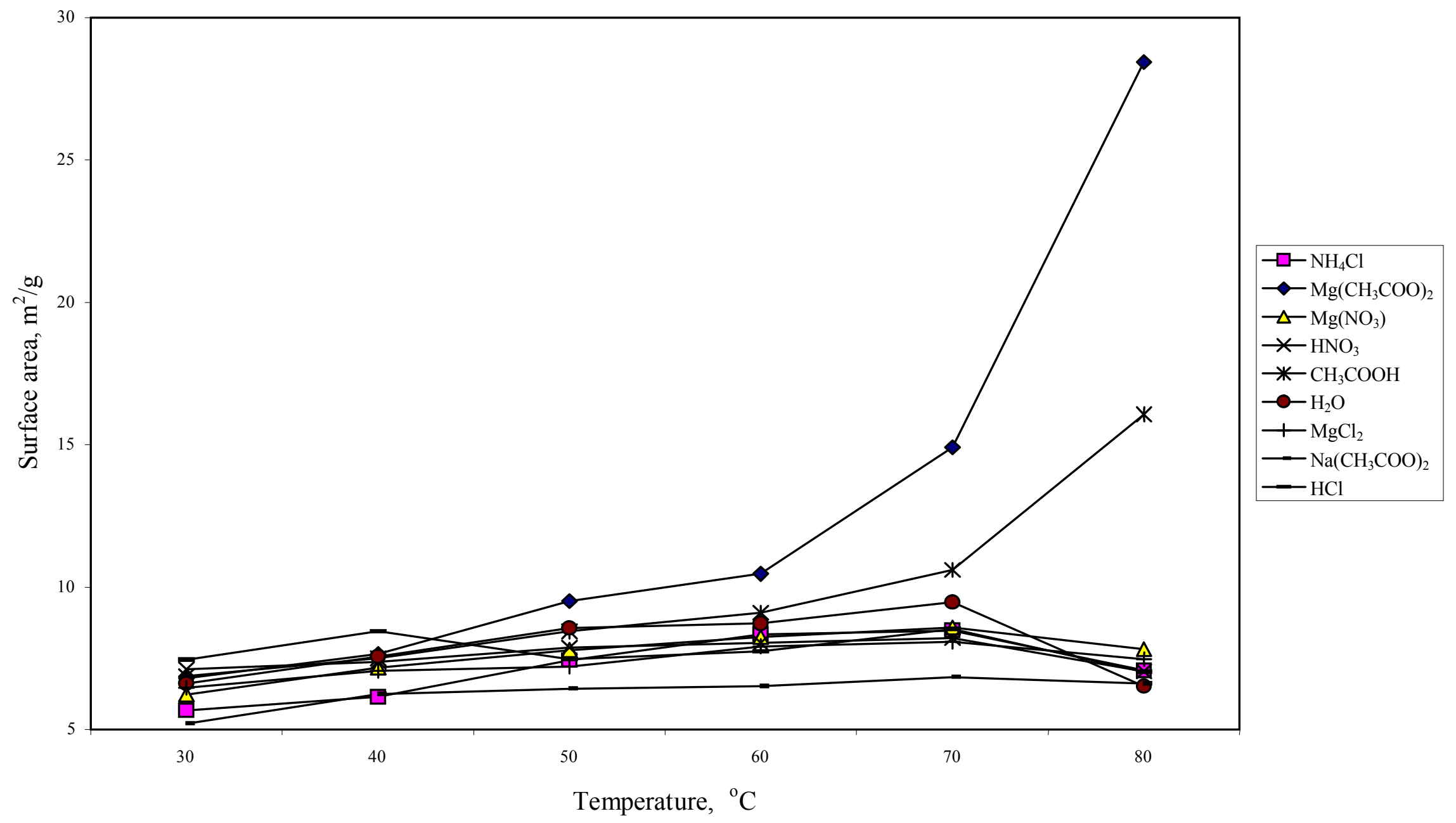

Figure 4. The variation of product surface area with hydration temperature 